\title{
PRINCIPAIS PATÓGENOS ENTÉRICOS DE ORIGEM BACTERIANA E PARASITÁRIA, DE POTENCIAL ZOONÓTICO, EM GATOS DOMÉSTICOS
}

\author{
Carolina Lechinski de Paula ${ }^{1}$ \\ Carmen Alicia Daza Bolaños ${ }^{1}$ \\ Simony Trevizan Guerra ${ }^{1}$ \\ Márcio Garcia Ribeiro ${ }^{1}$
}

\begin{abstract}
RESUMO
Os patógenos de eliminação fecal figuram como uma das principais classes de microorganismos patogênicos para os humanos e animais, causando graves doenças entéricas e, ocasionalmente, extra-entéricas. Este grupo de organismos caracteriza-se por manterem-se viáveis e com capacidade infectante em condições hostis do ambiente, após a eliminação pelas fezes dos animais com e sem sinais entéricos. Devido ao contato cada vez mais estreito com os humanos, os animais de companhia são elos importantes na cadeia de transmissão de patógenos entéricos. Os gatos domésticos representam um grupo importante de animais carreadores de patógenos entéricos com potencial zoonótico, uma vez que possuem hábitos de caça, de estabelecer territorialidade e de auto-limpeza. Dentre os patógenos de veiculação fecal de gatos domésticos de potencial zoonótico para humanos, merecem destaque: Escherichia coli, Salmonella spp., Campylobacter spp., Clostridium spp. Rhodococcus equi, Giardia spp. e Cryptosporidium spp. O presente estudo revisou os principais patógenos bacterianos e parasitários de gatos domésticos com ênfase aos aspectos de virulência, epidemiológicos, sinais clínicos, controle e reflexos em Saúde Pública.
\end{abstract}

Palavras-chave: enteropatógenos, felinos, zoonose, virulência, epidemiologia.

\section{THE MAIN BACTERIAL AND PARASITIC ENTERIC PATHOGENS WITH ZOONOTIC POTENTIAL IN DOMESTIC CATS}

\begin{abstract}
Enteric pathogens eliminated in the feces are among the most important range group of pathogenic microorganisms to humans and animals causing severe enteric diseases and occasionally, non-enteric too. This group of microorganisms is characterized by wide viability and infective capacity even in adverse environmental conditions after feces elimination of animals with or without enteric signals. In consequence of the close contact with humans, pets are very important in the chain of transmission of enteric pathogens. Domestic cats have hunting, territorial and self-cleaning habits and therefore are an important group with enteric pathogens with zoonotic potential. The most important fecal pathogens present in domestic cats with human zoonotic potential are Escherichia coli, Salmonella spp., Campylobacter spp., Clostridium spp. Rhodococcus equi, Giardia spp. and Cryptosporidium spp. The purpose of this study was to review the major bacterial and parasitic pathogens of domestic cats regarding the virulence aspects, epidemiology, clinical sings, control and importance in public health.
\end{abstract}

Keywords: enteropathogens, cats, zoonosis, virulence, epidemiology.

\footnotetext{
${ }^{1}$ Departamento de Higiene Veterinária e Saúde Pública. Área de Enfermidades Infecciosas dos Animais. UNESP-FMVZBotucatu. Contato principal para correspondência.
}

Paula CL, Bolaños CAD, Guerra ST, Ribeiro MC. Principais patógenos entéricos de origem bacteriana e parasitária, de potencial zoonótico, em gatos domésticos. Vet. e Zootec. 2017 Set.; 24(3): 453-467. 


\title{
PRINCIPALES PATÓGENOS ENTÉRICOS DE ORIGEN BACTERIANO Y PARASITARIO, CON POTENCIAL ZOONÓTICO, EN GATOS DOMÉSTICOS
}

\author{
RESUMEN
}

Los patógenos de eliminación fecal figuran como una de las principales clases de microorganismos patogénicos para los humanos y animales, causando graves enfermedades entéricas y ocasionalmente, extra entéricas. Este grupo de microorganismos se caracteriza por mantenerse viable y con capacidad infectante en condiciones hostiles del ambiente, posterior a la eliminación por las heces de animales con y sin signos entéricos. Debido al contacto cada vez más estrecho con los humanos, los animales de compañía son eslabones importantes en la cadena de transmisión de patógenos entéricos. Los gatos domésticos representan un grupo importante de animales transportadores de patógenos entéricos con potencial zoonótico, una vez que poseen hábitos de caza, de establecer territorialidad y de auto limpieza. Entre los patógenos de transmisión fecal de gatos domésticos con potencial zoonótico para humanos, se destacan: Escherichia coli, Salmonella sp., Campylobacter spp., Clostridium spp. Rhodococcus equi, Giardia sp. y Cryptosporidium spp. El presente estudio revisó los principales patógenos bacterianos y parasitarios de gatos domésticos con énfasis en los aspectos de virulencia, epidemiológicos, signos clínicos, control y reflejos en Salud Pública.

Palabras clave: enteropatógenos, felinos, zoonosis, virulencia, epidemiología.

\section{INTRODUÇÃO}

Os animais de companhia, especialmente cães e gatos, desempenham papel importante na sociedade $(1,2)$, pois servem, entres outros, para entretenimento e companhia de muitas famílias, contribuindo para o desenvolvimento físico, social e emocional das crianças e bemestar de seus proprietários (1).

Segundo dados da Abinpet, a população mundial de animais de estimação alcançou 1,5 bilhões em 2012. Em 2013, no Brasil, a Pesquisa Nacional da Saúde realizada pelo IBGE estimou que $44,3 \%$ dos domicílios do país possuíam pelo menos um cão e $17,7 \%$ dos domicílios possuíam ao menos um gato. A população de cães e gatos em domicílios brasileiros foi estimada em 52,2 milhões e 22,1 milhões, respectivamente (3). Na Europa e nos Estados Unidos, os gatos já superam os cães como os animais mais populares. No Brasil, também se observa essa tendência, visto que a população de felinos domésticos cresce mais do que a canina (4).

Diante desse cenário, onde é cada vez mais crescente o número de animais integrantes de muitas famílias, é inevitável o contato próximo entre humanos e animais domésticos, ou mesmo com seu ambiente de criação ou habitat, possibilitando condições favoráveis para a transmissão de micro-organismos patogênicos (5), constituindo fator de risco para ocorrência de várias zoonoses (1).

Os patógenos entéricos representam, mundialmente, grande impacto em Saúde Pública, especialmente em regiões tropicais (6). Essa classe complexa de micro-organismos pode ser considerada como uma das mais patogênicas para humanos e animais (7), agrupando agentes de origem bacteriana, viral e parasitária (6). O estabelecimento de infecção por esses agentes entéricos ocorre geralmente pela contaminação de alimentos de origem animal, água, verduras e frutas (7).

Os gatos domésticos são considerados um grupo preocupante de animais para os profissionais da saúde como carreadores de patógenos entéricos com potencial zoonótico (8), uma vez que possuem hábitos de caça, de estabelecer ampla territorialidade, hábitos de autolimpeza e de proximidade ou mesmo certa promiscuidade na interação com os proprietários. 
Os agentes com potencial zoonótico são de especial interesse para crianças, idosos, gestantes ou imunocomprometidos, que representam grupos com maior susceptibilidade às infecções. As crianças estão mais expostas a agentes provenientes de animais domésticos devido às deficiências na higiene, maior contato físico com esses animais e com o ambiente doméstico (5).

Dentre os patógenos bacterianos e parasitários de eliminação fecal com reconhecido potencial zoonótico, relacionados à graves doenças nos humanos, merecem destaque: Escherichia coli, Salmonella spp., Clostridium spp., Campylobacter spp., Rhodococcus equi, Giardia spp. e Cryptosporidium spp. (7-15).

São escassos os estudos conduzidos na investigação dos principais patógenos de veiculação fecal, bem como marcadores de virulência desses micro-organismos em gatos. Estudos nesse contexto são fundamentais para identificar a ocorrência destes patógenos em animais com e sem sinais entéricos, nas coinfecções, diferenças de ocorrência conforme o ambiente, rural ou urbano, dos animais, a virulência dos agentes e os reflexos dos animais domésticos como fontes de infecção de patógenos de eliminação fecal para os humanos.

Neste contexto, o presente estudo revisou os principais patógenos de origem bacteriana e parasitária de gatos domésticos com potencial zoonótico, com ênfase aos aspectos de virulência, epidemiológicos, sinais clínicos, controle e reflexos em Saúde Pública.

\section{REVISÃO DE LITERATURA}

\section{Escherichia coli}

O gênero Escherichia, pertencente à família Enterobacteriaceae, é composto por várias espécies, mas somente E. coli é considerada patogênica para animais e humanos (10), representando, provavelmente, a espécie bacteriana mais conhecida e isolada de amostras clínicas (16).

E. coli são micro-organismos aeróbicos ou anaeróbios facultativos, fermentadores de glicose e outros açúcares, que apresentam morfologia de bacilos ou cocobacilos gramnegativos, não esporulados, com até $2 \mu \mathrm{m}$ de comprimento $(12,16)$. A espécie compreende grande número de grupos e tipos sorológicos. A sorotipagem de E. coli é baseada na identificação de antígenos "O" (somático), "H" (flagelar), "K" (capsular) (10,17). São conhecidos atualmente 174 antígenos "O", 57 antígenos " $\mathrm{H}$ " e 100 antígenos "K", porém nem todas as estirpes de $E$. coli apresentam os três tipos de antígeno simultaneamente (10).

A colonização do trato intestinal dos mamíferos por E. coli ocorre logo após o nascimento, a partir de fontes ambientais Estes micro-organismos persistem como importantes membros da microbiota do intestino durante toda a vida dos animais e humanos (12).

Nos animais, as infecções clínicas por linhagens patogênicas de E. coli podem estar limitadas aos intestinos (com o desenvolvimento de enfermidades como a colibacilose e a diarreia neonatal) ou infecções extraentéricas. A septicemia e a toxemia são manifestações clínicas de infecções sistêmicas. A bactéria pode desenvolver infecções não entéricas, principalmente no trato urinário, glândulas mamárias e útero. Estirpes que causam enterocolite geralmente não pertencem à microbiota de animais saudáveis, pois resultam da infecção por contato direto com animais clinicamente ou subclinicalmente infectados, ou pela ingestão de alimentos ou água contaminados (12).

Em humanos, a bactéria pode gerar graves distúrbios gastrintestinais, quadros de septicemia, infecções urinárias e meningite do recém-nascido (18).

A habilidade de $E$. coli de causar doença em humanos e animais está diretamente relacionada a vários fatores de virulência localizados em genes plasmidiais e/ou cromossomais (19). Os fatores de virulência presentes em estirpes patogênicas de $E$. coli 
incluem, principalmente, cápsula, fatores de adesão, toxinas, lipopolisacarídeos, sistemas de aquisição de ferro, mecanismos de resistência e invasinas (12).

A aderência de E. coli é mediada por estruturas proteicas localizadas na superfície bacteriana, denominadas adesinas, divididas em fimbriais e não fimbriais. As adesinas fimbriais são codificadas pelos genes fim (fímbria tipo 1), pap (fímbria P) e $s f a$ (fímbria S). As adesinas não fimbriais (codificadas por $a f a$ ) são proteínas de membrana constituintes da cápsula. Ambos tipos de adesina agregam patogenicidade ao micro-organismo, especialmente às cepas enterotoxigênicas e uropatogênicas (20). Algumas linhagens de E. coli são produtoras de exotoxinas, com destaque para hemolisinas (codificadas pelo gene hly), enterotoxina termolábil (LT), enterotoxina termoestável (ST), verotoxina ou toxina de Shiga (VT/ Stx) e fator necrosante citotóxico (codificado pelo gene cnf) $(12,19)$. E coli apresenta também endotoxinas ou LPS (lipopolissacarídeos) que são estruturas intrínsecas de bactérias gram-negativas, ancoradas na parede celular, associadas com choque endotóxico (10).

No Japão, Yuri et al. (21) verificaram a presença de fatores de virulência em linhagens de E. coli isoladas de urina de cães e gatos com ITU e fezes de animais hígidos. Foram identificados os genes pil, pap, sfa, hly e cnfl, que são fatores de virulência também identificados em humanos, denotando riscos em Saúde Pública (21).

Recentemente as linhagens patogênicas de E. coli causadoras de diarreia ou outros distúrbios entéricos em humanos e animais foram organizadas em sete classes: enteropatogênicas (EPEC), enterotoxigênicas (ETEC), enterohemorrágicas (EHEC), enteroinvasoras (EIEC), enteroagregativas (EAggEC), de aderência difusa (DAEC) e necrotoxigênicas (NTEC). As linhagem patogênicas extra-entéricas (ExPEC) incluem as uropatogênicas (UPEC) e as que causam meningite neonatal (NMEC) (22). Estas classes diferem em sua patogenia bem como em fatores de virulência, pertencendo a grupos distintos de sorotipos. No contexto das zoonoses, a categoria que recebe maior preocupação são as enterohemorrágicas, por causar severas manifestações clínicas (7).

As EHEC produzem duas principais formas antigênicas de toxina de Shiga, Stx 1 e Stx2, também conhecidas como verocitotoxinas (VT1 e VT2) $(16,22)$. Essas toxinas se ligam nas células endoteliais vasculares e induzem necrose, microtrombose e trombocitopenia (22) Em humanos, as EHEC têm sido associadas com quadros de diarreia, colite hemorrágica (HC) e síndrome urêmica hemorrágica (HUS). A HUS é a principal complicação das infecções causadas por EHEC, caracterizada por anemia hemolítica, trombocitopenia e falha renal aguda (10).

E. coli $\mathrm{O} 157: \mathrm{H7}$ foi o primeiro de vários sorotipos produtores de toxina Shiga que causam reconhecidamente a doença em humanos, comumente adquirido por ingestão de carne ou água contaminados, com casos documentados principalmente nos Estados Unidos, Europa e Japão (22). Os hambúrgueres tem sido a causa de múltiplos surtos da doença, fato que se deve à presença desse sorotipo nas fezes de bovinos. Embora O157: H7 seja o sorotipo protótipo de EHEC patogênica, vários outros sorotipos produtores de Shiga toxina foram reconhecidos em outros países como O26:H11, O48:H21, O103:H2, O111:NM e O145:NM (16).

Cerca de 1\% dos bovinos eliminam o sorotipo 0157:H7 pelas fezes. No entanto, ao contrário dos humanos, os bovinos apresentam resistência ao sorotipo e não desenvolvem manifestações clínicas (23). Outras espécies animais, como os felinos domésticos, podem servir como reservatórios de E coli patogênicas. Busch et al. (24) relataram, na Alemanha, o primeiro caso de isolamento concomitante de E. coli enterohemorrágica das fezes de uma criança com sinais entéricos e de seu felino doméstico assintomático. Em cultivos repetidos das fezes do gato foi identificada E. coli EHEC 0145:H com a mesma patogenicidade e padrão genético da linhagem isolada da criança, reforçando o risco de transmissão de $E$. coli patogênicas dos animais para humanos (24).

Paula CL, Bolaños CAD, Guerra ST, Ribeiro MC. Principais patógenos entéricos de origem bacteriana e parasitária, de potencial zoonótico, em gatos domésticos. Vet. e Zootec. 2017 Set.; 24(3): 453-467. 
O risco potencial de animais de companhia, particularmente de felinos, no ciclo epidemiológico da infecção humana por linhagens patogênicas de $E$. coli ainda não é totalmente esclarecido. No Brasil, são praticamente inexistentes estudos que avaliem a ocorrência dos principais fatores de virulência de E. coli isolados de fezes de gatos sem sinais entéricos, particularmente de genes relacionados a estirpes de potencial zoonótico.

\section{Salmonella spp.}

O gênero Salmonella é pertencente à família Enterobacteriaceae e relacionado a doenças entéricas e extra-entéricas em animais e humanos. A salmonelose figura como uma das principais zoonoses em todo o mundo (11). Nos últimos anos, a classificação e nomenclatura de Salmonella spp. sofreram diversas modificações (25). Atualmente, o gênero é dividido em duas espécies: Salmonella entérica (que compreende a maioria dos sorotipos patogênicos), subdividida em seis subspécies (enterica, salamae, arizonae, diarizonae, houtenae e indica) e Salmonella bongori, comumente não patogênica $(11,16,25)$.

O gênero contém mais de 2500 sorotipos identificados com base em antígenos somáticos $(\mathrm{O})$ e flagelares $(\mathrm{H})$ e, por vezes, antígenos capsulares (K) (12). A maioria desses sorotipos pertence a $S$. enterica subespécie entérica (16).

$S$. enterica é a espécie mais patogênica e têm sido relacionada a quadros de gastroenterite, pneumonia, septicemia e, eventualmente, abortamentos nos animais e humanos (7). Os sorotipos frequentemente envolvidos em casos e surtos de salmonelose em humanos são $S$. Enteritidis e $S$. Typhimurium (26).

Salmonella spp. são bacilos gram-negativos, não formadores de esporos, anaeróbicos facultativos. A maioria das espécies apresenta motilidade e não fermenta a lactose (11). Os micro-organismos são ubíquos e possuem alta resistência ambiental, podendo colonizar grande variedade de mamíferos, aves, répteis e insetos (27).

A patogênese da infecção por Salmonella ainda não é totalmente esclarecida em certos aspectos, particularmente com relação à produção de toxinas e lesões celulares. Parte da virulência da bactéria está intimamente ligada à capacidade de invasão e multiplicação intracelular (12). A ação invasora das salmonelas é um processo complexo, que envolve genes cromossômicos e plasmidiais (25). Após ingestão e passagem pelo estômago, a bactéria se adere à mucosa intestinal, é internalizada em um vacúolo, se multiplica e pode ser liberada na corrente sanguinea ou linfática. Esses processos são regulados basicamente por dois grupos de genes, as ilhas de patogenicidade (PAI). PAI I codifica as proteínas de invasão (Ssps), enquanto a PAI II contém genes que permitem evasão da bactéria dos mecanismos de defesa imune do hospedeiro (27).

A resistência à digestão por fagócitos facilita a disseminação do micro-organismo no hospedeiro. O processo é parcialmente dependente do comprimento das cadeias do antígeno O do lipopolissacarídeo (LPS) da parede celular. Quanto mais longas as cadeias menor é a interação dos componentes do sistema complemento com a membrana bacteriana. O LPS também é responsável pelos efeitos endotóxicos da infecção, contribuindo para a resposta inflamatória que lesa as células intestinais, servindo como mediador em quadros de choque endotóxico e septicemia (12).A salmonelose humana é uma enfermidade de distribuição mundial, com ocorrência de milhões de casos por ano em todo o mundo, resultando em mais de cem mil óbitos (26). A transmissão do patógeno para humanos é geralmente por via oralfecal ou relacionada a toxinfeções por consumo de alimentos de origem animal (ovos, carnes, aves e leite), água e fômites contaminados. Alimentos de origem vegetal também têm sido implicados na transmissão do patógeno (7). Outra via que deve ser considerada na transmissão é representada pelo contato direto de animais portadores, geralmente assintomáticos, com humanos (26).

Os grupos de maior vulnerabilidade (risco) para a doença são crianças, idosos, e indivíduos imunossuprimidos ou hospitalizados (7). A gastroenterite aguda é a manifestação 
comum da doença em humanos, determinando sinais de vômito, diarreia, febre, cólicas abdominais, mialgia e cefaléia (27). Outras apresentações clínicas incluem septicemia, infecção do trato urinário, osteomielites, pneumonia e meningite $(25,28)$. Ainda, qualquer sorotipo de salmonela pode propiciar manifestação de febre entérica, habitualmente com febre baixa e diarreia, exceto nos casos de febre tifóide ( $S$. Typhi) em que a clínica é mais grave (16).

Salmonella spp. pode ser identificada na microbiota fecal de animais domésticos, com e sem sinais entéricos. Os animais eliminam o micro-organismo de maneira intermitente pelas fezes. A infecção dos animais ocorre predominantemente pelo consumo de alimentos e água contaminados por fezes ou pelo hábito da coprofagia, comum nos animais jovens. No entanto, outras vias como a umbilical, geniturinária e transplacentária também são observadas nas infecções em animais domésticos $(23,29)$. Neste contexto, merecem preocupação os animais de companhia como portadores sãos, em virtude da proximidade de gatos e cães dos proprietários, particularmente para grupos de maior vulnerabilidade, como crianças e idosos (7).

Os sinais clínicos de salmonelose em animais são entéricos e ocasionalmente extraentéricos. A maioria dos quadros entéricos são agudos e se iniciam entre 3 a 5 dias após exposição ao micro-organismo, ou são secundários à situações de estresse em animais portadores. Nos animais muito jovens ou velhos predominam sinais clínicos graves. O quadro inicial se caracteriza por febre alta, prostração e anorexia, seguidos de êmese, dor abdominal e diarreia mucóide. Animais gravemente afetados apresentam membranas mucosas pálidas, fraqueza, sinais de desidratação acentuada, colapso cardiovascular e choque (29).

Os gatos aparentam certa resistência imune contra o desenvolvimento da salmonelose clínica, ficando a doença restrita a casos esporádicos. Infeccções extraintestinais por salmonelas em gatos têm sido descritas como pneumonia, nefrite e cistite (29).

A incidência de salmonela em animais de companhia é variável entre os autores e o risco que esses animais representam para a transmissão do patógeno para os humanos depende das condições de criação desses animais e o nível de contato com os proprietários. Felinos domésticos são potenciais carreadores de Salmonella spp., particularmente os animais errantes ou com acesso livre à rua, onde o contato com materiais contaminados é mais frequente. $\mathrm{O}$ comportamento de caça observado na espécie também predispõe à colonização pela bactéria, principalmente pelo hábito de captura de pássaros, ratos e alguns insetos (30).

\section{Clostridium spp.}

O gênero Clostridium pertencente à família Clostridiaceae. É composto por mais de 200 espécies (31). Os micro-organismos se apresentam morfologicamente como bacilos grampositivos, anaeróbicos e formadores de endósporos. São ubíquos, encontrado no solo, água e esgotos, e como parte da microbiota entérica de humanos e animais $(12,27)$. A maioria das espécies é saprófita e não patogênica, mas algumas são causa de graves enfermidades como tétano ( $C$. tetani), botulismo ( $C$. botulinum, $C$. baratii, $C$. butyricum), mionecrose ou gangrena gasosa (C. perfringens, $C$. novyi, $C$. septicum, $C$. histolyticum) e diarreia e colite $(C$. perfringens, $C$. difficile) [27].

C. perfringens é importante espécie causadora de enterite e enterotoxemia, tanto em humanos quanto animais (32). O micro-organismo é dividido em cinco tipos (A-E), com base na produção de uma ou mais toxinas (alfa, beta, épsilon e iota) [27]. Adicionalmente, algumas linhagens produzem enterotoxina, toxina beta 2 e toxina de enterite necrótica (NetB), diretamente relacionadas à patogênese de algumas clostridioses (33).

C. perfringens é responsável por diversas infecções humanas, geralmente como agente primário de intoxicações alimentares (27). No Brasil, C. perfringens é relatado como o quarto agente mais frequente das doenças transmitidas por alimentos (34). A doença é causada pela ingestão de alimentos (especialmente carne vermelha e aves) contaminados com os esporos de parasitária, de potencial zoonótico, em gatos domésticos. Vet. e Zootec. 2017 Set.; 24(3): 453-467. 
C. perfringens tipo A. Os esporos são ativados com o calor da cocção do alimento, permitindo a germinação das formas vegetativas, que se multiplicam rapidamente. Após ingestão, as formas vegetativas sofrem processo de esporulação no intestino, liberando a enterotoxina. Ocorre então ligação da enterotoxina às microvilosidades intestinais, causando alteração na permeabilidade e perda de fluidos $(7,27)$. Os indivíduos acometidos apresentam clínica de início súbito, com diarreia e cólica abdominais. O curso da doença é curto, com resolução em poucos dias, muitas vezes sem necessidade de tratamento médico. Apesar de raramente causar morte, a doença pode ocorrer em surtos de proporção variável no caso de fontes de alimento comum, além de ser potencialmente fatal em pessoas debilitadas, idosos e crianças (7).

Nos animais, o micro-organismo é agente causal de enterocolite necrosante de suínos lactentes e desmamados, enterite necrótica de frangos de corte e enterite de equinos (12), além de enterotoxemia em pequenos ruminantes (32). O envolvimento de $C$. perfringens tipo A como enteropatógeno de cães e gatos ainda não é totalmente compreendido. A bactéria pode ser agente primário de quadros leves à graves de diarreia. Alguns autores sugerem o agente como oportunista nessas espécies (33).

Os humanos e os animais são considerados reservatórios de C. perfringens, eliminando a bactéria pelas fezes. Cães e gatos saudáveis podem colaborar para contaminação ambiental e de alguns fômites, constituindo fontes de infecção para humanos (7).

C. difficile é outra espécie do gênero Clostridium de relevância como enteropatógeno. $\mathrm{O}$ agente é ubíquo da natureza, isolado de solo, água e microbiota intestinal de humanos e animais. Assim como outras espécies do gênero tem característica morfológica de bastonete gram-positivo, de difícil isolamento por sua condição de anaerobiose estrita. Diferentemente de $C$. perfringens, as colônias não são hemolíticas (16).

A infecção por $C$. difficile é a causa mais comum de diarreia associada ao uso de antimicrobianos em humanos hospitalizados (35). Medicamentos imunossupressores, principalmente os quimioterápicos, também parecem favorecer o desenvolvimento da doença. A diarreia varia de autolimitante e relativamente benigna, até colite pseudomenbranosa, quadro grave e potencialmente fatal (27).

As fontes de infecção de $C$. difficile são representadas por indivíduos doentes e portadores assintomáticos que eliminam esporos do bacilo com as fezes. A transmissão ocorre principalmente de pessoa a pessoa, via fecal-oral ou por contato indireto com objetos e utensílios contaminados pelos esporos (36).

A infecção por $C$. difficile inicia-se com a ingestão do micro-organismo na forma vegetativa ou por esporos, reconhecida como forma de extrema resistência ambiental. Os esporos sobrevivem à acidez gástrica e germinam no cólon na forma vegetativa. $\mathrm{O}$ uso de antimicrobianos pode propiciar a colonização de $C$. difficile devido alteração da microbiota intestinal, diminuindo a competição entre os micro-organismos e facilitando a transformação dos esporos da bactéria em células vegetativas (36).

As estirpes toxigênicas produzem duas toxinas, uma enterotoxina (toxina A-TcdA) e uma citotoxina (toxina B-TcdB) (27,35). A lesão intestinal parece ser iniciada pela enterotoxina, que possui receptores na lâmina basal das células epiteliais, sendo quimiotática para neutrófilos e estimulando a infiltração de células polimorfonucleares no íleo, com liberação de citocinas. A TcdA também produz um efeito citopático, resultando no rompimento da junção célula-célula, permitindo a ação da toxina $\mathrm{B}$, amplificando a lesão e aumentando a permeabilidade da parede intestinal com consequente diarreia. A TcdB leva à destruição do citoesqueleto celular $(27,37)$.

Além disso, as toxinas A e B atuam diretamente nas células epiteliais da mucosa intestinal, ativando a cascata inflamatória e resultando em aumento de lesão tecidual, extravasamento de fluido e morte celular (37). As proteínas de superfície (SLPs) também são importantes na patogenia da infecção, permitindo a adesão de $C$. difficile ao epitélio intestinal, com produção local de toxinas e dano tecidual (27). 
Algumas cepas de $C$. difficile produzem um terceiro tipo de toxina, a toxina binária (CDT) (27,35). A importância clínica dessa toxina é motivo de discussão e sua real importância como fator de virulência ainda é desconhecida. Acredita-se, porém, que a toxina binária possa agir em sinergismo com as toxinas A e B, aumentando a lesão do citoesqueleto, com agravamento do quadro clínico (38).

Em animais, $C$. difficile é causa de diarreia e colite em potros de 2 semanas de idade e leitões neonatos. Em equinos adultos também há associação da infecção com uso de antimicrobianos (23). São raros os relatos de manifestação da doença em cães (33) e gatos (39).

A transmissão de $C$. difficile de animais de companhia para humanos ainda não foi documentada. Borriello et al. (40) levantaram a hipótese de animais domésticos como reservatórios e transmissores de $C$. difficile aos humanos, a partir do isolamento da bactéria nas fezes de cães e gatos.

O real impacto dos animais domésticos, em especial felinos, na epidemiologia das doenças causadas por $C$. perfringens e $C$. difficile não é totalmente esclarecido. São necessários estudos que investiguem a eliminação desses agentes pelos animais, a fim de estabelecer os riscos de transmissão para humanos.

\section{Campylobacter spp.}

Campylobacter spp. são bactérias pertencentes à família Campylobacteriacea. $\mathrm{O}$ gênero Campylobacter agrupa 23 espécies e 8 subspécies, com destaque para $C$. jejuni como espécie envolvida na maioria das campilbacterioses entéricas em humanos e animais domésticos (15).

Os micro-organismos desse gênero são bacilos gram-negativos, com motilidade, característica determinada pela presença de flagelo monopolar ou bipolar monotríquio $(12,27)$. A maioria das espécie é fastidiosa, exigindo meios enriquecidos ou seletivos, com incubação em atmosfera de microaerofilia (5 a $10 \%$ de $\mathrm{O}_{2}$ e 1 a $10 \%$ de $\left.\mathrm{CO}_{2}\right)(12,15)$.

Campylobacter jejuni é a espécie geralmente associada à enterite e diarreia em cães, gatos e humanos, além de outros animais domésticos e selvagens (41). O enteropatógeno coloniza os intestinos delgado e grosso, onde se adere e prolifera. Os flagelos e o LPS atuam como adesinas, permitindo aderência da bactéria às células epiteliais e mucosa intestinal. A adesão é facilitada pelo movimento característico de "saca rolha" que garante maior superfície de contato (27).

Em gatos, as manifestações clínicas da campilobacteriose são pouco documentadas. Sinais entéricos, anorexia e desidratação são predominantes em animais jovens. Frequentemente observam-se animais coinfectados com os gêneros Giardia e Isospora (15).

A via de infecção, à semelhança de outros patógenos entéricos, é a fecal-oral, pela ingestão de alimentos ou água contaminados. Portadores assintomáticos podem eliminar a bactéria pelas fezes por longos períodos, representando riscos de transmissão direta ou contaminação ambiental (41).

Em humanos, a campilobacteriose se apresenta de forma esporádica ou em surtos. A doença pode acometer invidíduos de qualquer faixa etária, com destaque para crianças menores de dois anos de idade (7). Os sinais clínicos evidentes são vômito, diarreia, febre e dor abdominal.

Cães e gatos são considerados fatores de risco nas infecções por Campylobacter spp. em humanos (42). Usualmente são incriminados como potenciais transmissores da bactéria os animais diarreicos e recém adquiridos de canis/gatis (41), embora o micro-organismo também seja isolado de fezes de animais assintomáticos. Porém, a epidemiologia de infecções de espécies de Campylobacter é complexa, necessitando de mais estudos que determinem as interações patógeno-hospedeiro, que possam subsidiar ações de controle/profilaxia. 


\section{Rhodococcus equi}

As bactérias do gênero Rhodococcus pertencem à ordem Actinomycetales, que incluem outros gêneros importantes como Corynebacterium, Mycobacterium, Trueperella e Nocardia. Rhodococcus equi (R. equi) é a espécie mais importante do gênero, causadora de infecções em humanos e animais (43). Morfologicamente se apresentam como cocos ou cocobacilos grampositivos, fracamente álcool-ácido resistentes, aeróbicos, não formadores de esporos, encapsulados, intracelulares facultativos e imóveis $(7,27,43)$. As colônias em meio sólido são lisas com bordas irregulares, mucóides, com coloração que varia do branco ao rosa-salmão, dependendo do tempo de incubação $(27,43)$.

$R$. equi é amplamente distribuído no solo e habitante transitório do trato intestinal de animais (12). Está presente nas fezes de ruminantes, suínos e, principalmente, equinos, que servem como carreadores da bactéria, auxiliando em sua manutenção ambiental $(23,44)$.

A rodococose afeta potros entre 1 e 6 meses de idade, caracterizada por broncopneumonia crônica supurativa e abscessos pulmonares. As primeiras manifestações clínicas em potros podem incluir ligeiro aumento da frequência respiratória e febre baixa. Posteriormente, há dispneia intensa, letargia e febre alta $(9,12)$.

Assim como em equinos adultos, a doença em outras espécies é rara, geralmente associada a quadros de imunossupressão, ocorrendo sob forma de enterite, linfadenite, abortamento, mastite, dermatite, piometra e abscessos cutâneos $(9,44)$. Em suínos, é comum o isolamento da bactéria de linfonodos submandibulares e mesentéricos (9).

A patogenicidade e virulência de $R$. equi está intimamente ligada à capacidade de sobrevivência e replicação da bactéria no interior de macrófagos, que resulta na destruição das células (44). Nas últimas décadas foram reconhecidas proteínas associadas à virulência (Vap), utilizadas como marcadores de patogenicidade, principalmente em estudos epidemiológicos (45).

As linhagens altamente virulentas contém um grande plasmídeo de 85 a 90kb, com genes responsáveis pela expressão de proteínas VapA de 15 a $17 \mathrm{kDa}$ (genes vapA,-C,-D,-E,$\mathrm{G}$ e pseudogenes vap $\mathrm{F}$,-I e $-\mathrm{X}$ ) isoladas predominantemente em potros com clínica pulmonar e menos frequentemente em humanos. As linhagens de virulência intermediária apresentam plasmídios de 79 a 100kb, com expressão de proteínas VapB de $20 \mathrm{kDa}$ (genes vapB,-J, -K1,K2,-L e M), identificadas na linfadenite em suínos e em humanos com Aids (45,46). As linhagens que não se enquadravam no perfil de virulência supracitado eram denominadas avirulentas, encontradas no solo, fezes de animais domésticos e criatórios de equinos e por vezes, isoladas de humanos (46). Porém, estudo recente de epidemiologia molecular demonstrou que muitos isolados considerados sem plasmídios Vap A ou Vap B possuíam um terceiro tipo de virulência, o VapN, de $120 \mathrm{~kb}$, identificado em bovinos e humanos com e sem Aids $(45,47)$. Evidências suportam que as linhagens Vap $\mathrm{N}$ podem ser transmitidas para os humanos pelo consumo de carne, assumindo um potencial zoonótico (47).

Outros fatores de virulência do agente que permitem a evasão do sistema imune incluem polissacarídeos capsulares e ácidos micólicos na parede celular, além de várias exoenzimas (12).

$R$. equi é considerado em muitos países patógeno emergente em humanos, causando infecção oportunista em pacientes imunocomprometidos. Os maiores grupos de risco para a rodococose são os indivíduos HIV positivos, os pacientes que receberam transplantes de órgãos e aqueles em tratamento com quimioterápicos ou corticosteroides (44).

A rodococose em humanos se caracteriza por pneumonia granulomatosa com lesões que podem mimetizar a tuberculose, tornando-se lentamente progressiva e com desenvolvimento de cavitações. Outras manifestações incluem endolftalmite, osteomielite, pleurisia com efusão, abscessos cutâneos e no sistema nervoso central (16). A inalação do micro-organismo é, provavelmente, a via mais comum de transmissão da doença pulmonar em animais e humanos. Nos casos de rodococose intestinal a transmissão ocorre aparentemente pela parasitária, de potencial zoonótico, em gatos domésticos. Vet. e Zootec. 2017 Set.; 24(3): 453-467. 
ingestão de alimentos e água contaminados ou mesmo por deglutição de secreções pulmonares $(23,44)$.

Em animais de companhia a rodococose clínica é rara. As principais afecções envolvidas com a infecção por $R$. equi em cães e gatos são representadas por linfadenite, abscessos cutâneos, piotórax, pneumonia e lesões abscedantes em diversos órgãos, sendo a via transcutânea a principal porta de entrada para o agente. Tais infecções são mais comumente observadas em felinos, cujo comportamento agressivo em disputas territoriais e/ou por fêmeas favorece a veiculação da bactéria por arranhaduras ou lesões perfurocortantes. Em gatos, a rodococose está associada à coinfecção com doenças de base imunossupressivas, com destaque para o vírus da imunossupressão e da leucemia felina (48).

Apesar de frequente o isolamento de $R$. equi em fezes de animais de produção e, eventualmente, de humanos, raramente há relatos da presença do agente em fezes de cães (9). E também, até o presente momento não há relatos de isolamento da bactéria em fezes de felinos.

\section{Giardia spp.}

Giardia é um gênero de protozoários intestinais flagelados que infectam ampla gama de animais vertebrados. O gênero é composto por seis espécies que são distinguidas com base na morfologia e estrutura dos trofozoítas. Giardia duodenalis (sinonímia G. intestinalis, G. lamblia) é a espécie de distribuição mundial considerada agente etiológico da giardíase em grande variedade de mamíferos (49). Estudos moleculares têm demonstrado que $G$. duodenalis é uma espécie complexa e apresenta sete genótipos (A-G). Alguns genótipos foram detectados tanto em humanos quanto em animais, embora outros sejam hospedeiroespecíficos. Os gatos podem albergar o genótipo F ("gato-específico") e também ocasionalmente os genótipos $\mathrm{A}$ e $\mathrm{B}$, que representam os principais detectados em humanos (50).

Giardia spp. possui duas formas em seu ciclo de vida denominadas cisto e trofozoíta. Os trofozoítas são móveis e colonizam o trato intestinal. Nos felinos são encontrados principalmente em jejuno e íleo (49). Cada cisto contém dois trofozoítas e, após a ingestão, ocorre excistação no duodeno por exposição ao ácido gástrico e suco pancreático. Os dois trofozoítas contidos no cisto sofrem maturação e se anexam à borda em escova do epitélio das vilosidades intestinais, onde se multiplicam por fissão binária e depois encistam por mecanismo ainda não esclarecido. O período pré-patente da giardíase em gatos varia de 5 a 16 dias (média de 10 dias). Os trofozoítas também podem ser eliminados nas fezes, mas raramente sobrevivem por período significativo fora do hospedeiro (50).

Os sinais clínicos variam consideravelmente entre os animais. A gravidade da sintomatologia é influenciada pela idade, estresse, resposta imunológica e estado nutricional, assim como as linhagens do parasita (51).

Giardia spp. é reconhecida como o parasita mais frequente entre as causas de diarreia em humanos, com estimativa de 280 milhões de infectados mundialmente por ano (52). As crianças e os animais jovens são particularmente suscetíveis às infecções pelo protozoário devido ao sistema imunológico não completamente desenvolvido (53). Os animais de companhia também estão associados com a transmissão direta da giardíase para os humanos, especialmente em ambientes endêmicos (54), embora não seja ainda estabelecido o real impacto desses animais como fontes de infecção. Pereira et al. (55) associaram o número de gatos na família como um dos fatores de risco da giardíase, em uma pesquisa realizada em hospitais pediátricos de Goiânia, Goiás, entre crianças hospitalizadas com diarréia. No estudo citado, o risco de giardíase aumentou cerca de $25 \%$ para cada gato adicional na família (55). 


\section{Cryptosporidium spp.}

Cryptosporidium spp. são protozoários parasitas de uma grande variedade de vertebrados, incluindo mamíferos, aves, répteis, anfíbios e peixes (56). Atualmente, existem pelo menos 20 espécies reconhecidas e 40 genótipos de Cryptosporidium (51). Destes, as cinco espécies $C$. hominis, $C$. parvum, C. meleagridis, $C$. felis e $C$. canis podem infectar humanos imunocompetentes e imunocomprometidos (56).

C. felis é transmitido por via oral-fecal. A infecção pode ocorrer diretamente pela coprofagia e pela ingestão de presas infectadas, ou por ingestão de alimentos ou água contaminados. Após a ingestão dos oocistos ocorre excistamento no trato gastrintestinal, libertando os esporozoítas que constituem a forma infecciosa do protozoário. Os esporozoítos invadem o epitélio intestinal, onde sofrem replicação assexuada e multiplicação sexuada. Os zigotos formados por reprodução sexuada formam oocistos de paredes espessas, contendo quatro esporozoítos, que são eliminados nas fezes (57).

Os sinais clínicos da doença em gatos são diarreia, anorexia e perda de peso. A diarreia é geralmente aquosa, sem muco, sangue, melena ou esforço. A maioria dos casos sintomáticos de criptosporidiose foram relatados em gatos com imunossupressão, com coinfecções por outros micro-organismos ou com doenças intestinais preexistentes (50). Em animais de companhia, a doença clínica está associada ao desmame, a deficiências nutricionais e a condições de superlotação em canis e/ou gatis (51).

Com o advento da Síndrome da Imunodeficiência Adquirida (Aids) na década de 1980, relatos de infecções oportunistas foram associados ao Cryptosporidium spp., que passou a ser considerado importante patógeno em humanos (13). Este parasito foi incluído nas doenças negligenciadas da Organização Mundial da Saúde por sua estreita relação com a população de baixo poder aquisitivo, precárias condições de saneamento básico e da qualidade da água consumida (58).

Em humanos, a doença é responsável por manifestações clínicas de diarreia e gastroenterites, apresentando-se como uma doença fatal em pacientes imunocomprometidos e que pode debilitar severamente indivíduos imunocompetentes (59).

Estudo recente no Brasil abordou a prevalência de Cryptosporidim sp. em amostras fecais de idosos e de seus felinos domésticos. A positividade para Cryptosporidium nos animais que conviviam com idosos foi muito elevada, evidenciando o risco de exposição desta parasitose em grupos populacionais considerados mais suscetíveis (60).

\section{CONSIDERAÇÕES FINAIS}

Os estudos envolvendo a ocorrência de patógenos entéricos na espécie felina abordam, em sua maioria, micro-organismos isolados, em especial, em animais com diarreia, embora seja conhecido que esses agentes possam estabelecer coinfecções e serem eliminados pelas fezes de gatos de modo subclínico ou inaparente. Também nota-se pouca preocupação na pesquisa dos principais patógenos de veiculação fecal no que tange a procedência do seu ambiente de criação, tampouco investigação dos fatores de virulência desses microorganismos, que permitam reconhecer o real impacto da patogenicidade dos isolados e as peculiaridades de ordem ambiental que possam favorecer a transmissão dos patógenos para os humanos. A presente revisão alerta para o potencial de gatos domésticos em albergar microorganimos entéricos, de origem bacteriana e parasitária, patogênicos aos humanos e demais espécies animais. A presença de diferentes patógenos nas fezes de gatos domésticos sinaliza para a necessidade de conscientização da população em geral pelos profissionais da saúde, sobre o potencial zoonótico desses micro-organismos, principalmente em virtude do contato cada vez mais estreito dos humanos e animais de companhia, especialmente gatos. 


\section{REFERÊNCIAS}

1. Robertson ID, Thompson RC. Enteric parasitic zoonoses of domesticated dogs and cats. Microbes Infect. 2002;4:867-73.

2. Wood L, Martin K, Christian H, Nathan A, Lauritsen C, Houghton S, et al. The pet factor companion animals as a conduit for getting to know people, friendship formation and social support. PLos One. 2015;10:1-17.

3. Instituto Brasileiro de Geografia e Estatística. Pesquisa nacional de saúde 2013. Rio de Janeiro: IBGE; 2015.

4. Yoko F. Mercado em constante evolução. Nutr Pet Horse. 2011;13:6-12.

5. Damborg P, Broens EM, Chomel BB, Guenther S, Pasmans F, Wagenaar JA, et al. Bacterial zoonoses transmitted by household pets: state-of-the-art and future perspectives for targeted research and policy actions. J Comp Pathol. 2016;155:S27-40.

6. Kato K, Ishiwa A. The role of carbohydrates in infection strategies of enteric pathogens. Trop Med Health. 2015;43:41-52.

7. Acha PN, Szyfres B. Zoonosis y enfermidades transmisibles comunes al hombre y a los animales. 3rd ed. Washington: Organización Panamericana de la Salud; 2003. v.1,2,3.

8. Shakespeare M. Zoonoses. 1st ed. London: Pharmaceutical press; 2002.

9. Prescott JF. Rhodococcus equi: an animal and human pathogen. Clin Microbiol Rev. 1991;4:20-34.

10. Trabulsi LR, Campos LC. Infecções por Escherichia. In: Veronesi R, Focaccia R. Tratado de infectologia. 2a ed. São Paulo: Atheneu; 2004. p.793-8.

11. Donnenberg MS. Enterobacteriaceae. In: Mandell GL, Bennett JE, Dolin R. Principles and practice of infectious diseases. 7th ed. Philadelphia: Elisevier; 2010. p.2815-901.

12. Quinn PJ, Markey BK, Leonard FC, Hartigans P, Fanning S, Fitzpatrick ES. Veterinary microbiology and microbial disease. 2nd ed. Oxford: Blackwell Science; 2011.

13. Cieloszyk J, Goñi P, García A, Remacha MA, Sánchez E, Clavel A. Two cases of zoonotic cryptosporidiosis in Spain by the unusual species Cryptosporidium ubiquitum and Cryptosporidium felis. Enferm Infecc Microbiol Clin. 2012;2:549-51.

14. Scorza AV, Lappin MR. Enteric protozoal infections. In: Greene CE. Infectious diseases of the dog and cat. 4th ed. St. Louis: Elsevier Saunders; 2012. p.785-92.

15. Giuffrida R. Infecções pelo gênero Campylobacter. In: Megid J, Ribeiro MG, Paes AC. Doenças infecciosas em animais de produção e de companhia. 1a ed. Rio de Janeiro: Rocca; 2016. p.347-55.

16. Winn Jr W, Allen S, Janda W, Koneman E, Procop G, Schreckenberger P, et al. Koneman. Diagnóstico microbiológico: texto e atlas colorido. 6a ed. Rio de Janeiro: Guanabara Koogan; 2008.

Paula CL, Bolaños CAD, Guerra ST, Ribeiro MC. Principais patógenos entéricos de origem bacteriana e parasitária, de potencial zoonótico, em gatos domésticos. Vet. e Zootec. 2017 Set.; 24(3): 453-467. 
17. Lior H. Classification of Escherichia coli. In: Gyles CL. Escherichia coli in domestic animals and humans. Wallingford: CAB International; 1994. p.31-71.

18. Nataro JP, Levine MM. Escherichia coli diseases in humans. In: Gyles CL. Escherichia coli in domestic animals and humans. Wallingford: CAB International; 1994. p.285-333.

19. Donnerberg MS, Whittam TS. Pathogenesis and evolution of virulence in enteropathogenic and enterohemorrhagic Escherichia coli. J Clin Invest. 2001;107:53948 .

20. Bower JM, Eto DS, Mulvey A. A Covert operation of uropathogenic Escherichia coli within the urinary tract. Traffic. 2005;6:18-31.

21. Yuri K, Nakata K, Katae H, Tsukamoto T, Hasegawa A. Serotypes and virulence factors of Escherichia coli strains isolated from dogs and cats. J Vet Med Sci. 1999;61:37-40.

22. Koenig A. Gram-Negative bacterial. In: Greene CE. Infectious diseases of the dog and cat. 4th ed. St. Louis: Elsevier Saunders; 2012. p.349-58.

23. Radostits OM, Gay C, Hinchcliff K, Constable P. Veterinary medicine: a textbook of the disease of cattle, horses, sheep, pigs, goats and horses. 10a ed. London: WB Saunders; 2007.

24. Busch U, Hormansdorfer S, Schranner S, Huber I, Bogner KH, Sing A. Enterohemorrhagic Escherichia coli coll excretion by child and her cat. Emerg Infect Dis. 2007;13:348-9.

25. Trabulsi LR, Campos LC, Lourenço R. Salmoneloses. In: Veronesi R, Focaccia R. Tratado de infectologia. 2a ed. São Paulo: Atheneu; 2004. p.878-85.

26-. World Health Organization. Salmonella (non-typhoidal) [Internet]. Geneva: Who; 2013 [cited 2015 Sept 8]. Available from: http://www.who.int/mediacentre/factsheets/fs 139/en/

27. Murray PR, Rosenthal KS, Pfaller MA. Microbiologia médica. 6a ed. São Paulo: Elsevier; 2010.

28. Nataro JP, Bopp CA, Fields PI, Kaper JB, Strockbine NA. Escherichia, Shigella, and Salmonella. In: Murray PR, Baron EJ, Jorgensen JH, Landry ML, Pfaller MA. Manual of clinical microbiology. 9th ed. Whashington: ASM Press; 2007. p.678-83.

29. Greene CE. Salmonellosis. In: Greene CE. Infectious diseases of the dog and cat. 4th ed. St. Louis: Elsevier Saunders; 2012. p.383-9.

30. Weese JS. Bacterial enteritis in dogs and cats: diagnosis, therapy, and zoonotic potential. Vet Clin Am Small Anim Pract. 2011;41:287-309.

31. Onderdonk AB, Garrett WS. Gas gangrene and other Clostridium associated diseases. In: Mandell GL, Bennett JE, Dolin R. Principles and practice of infectious diseases. 7th ed. Philadelphia: Elsevier; 2010. p.3103-9.

32. Megid J. Clostridioses. In: Megid J, Ribeiro MG, Paes AC. Doenças infecciosas em animais de produção e de companhia. 1a ed. Rio de Janeiro: Rocca; 2016. p.144-53. 
33. Silva ROS, Lobato FCF. Clostridium perfringens: a review of enteric diseases in dogs, cats and wild animals. Anaerobe. 2015;33:14-7.

34. Ministério da Saúde (BR). Secretaria de Vigilância em Saúde. Manual integrado de prevenção e controle de doenças transmitidas por alimentos. Brasília: Ministério da Saúde; 2010.

35. Rupnik M, Wilcox MH, Gerding DN. Clostridium difficile infection: new developments in epidemiology and pathogenesis. Nature. 2009;7:526-36.

36. Pereira NG. Infecção pelo Clostridium difficile. J Bras Med. 2014;102:27-49.

37. Megid J. Doenças associadas ao Clostridium difficile. In: Megid J, Ribeiro MG, Paes AC. Doenças infecciosas em animais de produção e de companhia. 1a ed. Rio de Janeiro: Rocca; 2016. p.184-7.

38. Gonçalves C, Decré D, Barbut F, Burghoffer B, Petit JC. Prevalence and characterization of a binary toxin (actinspecific ADP-ribosyltransferase) from Clostridium difficile. J Clin Microbiol. 2004;42:1933-9.

39. Clooten J, Kruth S, Arroyo L, Weese JS. Prevalence and risk factors for Clostridium difficile colonization in dogs and cats hospitalized in an intensive care unit. Vet Microbiol. 2008;129:209-14.

40. Borriello SP, Honour P, Turner T, Barclay F. Household pets as a potential reservoir for Clostridiumn difficile infection. J Clin Pathol. 1983;36:84-7.

41. Fox JG. Enteric bacterial infection. In: Greene CE. Infectious diseases of the dog and cat. 4th ed. St. Louis: Elsevier Saunders; 2012. p.370-4.

42. Wolfs TFW, Duim B, Geelen SP, Rigter A, Thomson-Carter F, Fleer A, et al. Neonatal sepsis by Campylobacter jejuni: genetically proven transmission from a household puppy. Clin Infect Dis. 2001;32:E97-9.

43. Meyer DK, Reboli AC. Other Coryneform Bacteria and Rhodococci. In: Mandell GL, Bennett JE, Dolin R. Principles and practice of infectious diseases. 7th ed. Philadelphia: Elsevier; 2010. p.2702-4.

44. Hines MT. Rhodococcus equi. In: Sellon DC, Long MT. Equine infectious diseases. 2nd ed. St. Louis: Saunders; 2014. p.287-302.

45. Ribeiro MG, Vargas AC. Rodococose. In: Megid J, Ribeiro MG, Paes AC. Doenças infecciosas em animais de produção e de companhia. 1a ed. Rio de Janeiro: Rocca; 2016. p.258-77.

46. Takai S. Epidemiology of Rhodococcus equi infections: a review. Vet Microbiol. 1997;56:167-76.

47. Valero-Rello A, Hapeshi A, Anastasi E, Alvarez S, Scortti M, Meijer WG, et al. An invertron-like linear plasmid mediates intracellular survival and virulence in bovine isolates of Rhodococcus equi. Infect Immun. 2015;83:2725-37.

Paula CL, Bolaños CAD, Guerra ST, Ribeiro MC. Principais patógenos entéricos de origem bacteriana e parasitária, de potencial zoonótico, em gatos domésticos. Vet. e Zootec. 2017 Set.; 24(3): 453-467. 
48. Greene CE, Prescott JF. Gram-Positive bacterial infections. In: Greene CE. Infectious diseases of the dog and cat. 4th ed. St. Louis: Elsevier Saunders; 2012. p.334-5.

49. Adam RD. Biology of Giardia lamblia. Clin Microbiol Rev. 2001;14:447-75.

50. Scorza AV, Lappin MR. Enteric protozoal infections. In: Greene CE. Infectious diseases of the dog and cat. 4th ed. St. Louis: Elsevier Saunders; 2012. p.785-92.

51. Thompson RCA, Palmer CS, O'Handley R. The public health and clinical significance of Giardia and Cryptosporidium in domestic animals. Vet J. 2008;177:18-25.

52. Lane S, Lloyd D. Current trends in research into the waterborne parasite Giardia. Crit Rev Microbiol. 2002;28:123-47.

53. Taylor MA, Catchpole J, Marshall RN, Green J. Giardiasis in lambs at pasture. Vet Rec. 1993;133:131-3.

54. Geurden T, Olson M. Giardia in pet and farm animals, and their zoonotic potential. In: Luján HD, Svärd S. Giardia a model organism. NewYork: SpringerWien; 2011. p.71-9.

55. Pereira MGC, Atwill ER, Barbosa AP. Prevalence and associated risk factors for Giardia lamblia infection among children hospitalized for diarrhea in Goiânia, Goiás State, Brazil. Rev Inst Med Trop São Paulo. 2007;49:139-45.

56. Xiao L, Fayer R, Ryan U, Upton SJ. Cryptosporidium taxonomy: recent advances and implications for public health. Clin Microbiol Rev. 2004;17:72-97.

57. Fayer R, Morganb U, Upton SJ. Epidemiology of Cryptosporidium: transmission, detection and identication. Int J Parasitol. 2000;30:1305-22.

58. Assis DC, Resende DV, Cabrine-Santos M, Correia D, Oliveira-Silva MB. Prevalence and genetic characterization of Cryptosporidium spp. and Cystoisospora belli in HIVinfected patients. Rev Inst Med Trop São Paulo. 2013;55:149-54.

59. Teunis PFM, Havelaar AH. Risk assessment for protozoan parasites. Int Biodeterior Biodegrad. 2002;9:122-46.

60. Pereira CRA, Ferreira AP. Ocorrência e fatores de risco da criptosporidiose em felinos de companhia de idosos. Rev Bras Geriatr Gerontologia. Rio de Janeiro. 2012;15:681-91.

Recebido em: 04/10/2016 Aceito em: 08/07/2017 